Research Article

\title{
Research on Optimal Proportion and Performance of Cement-Clay Slurry
}

\author{
Peili Su, ${ }^{1,2}$ Feng Liu $\mathbb{D}^{1}{ }^{1}$ Peng Yao, ${ }^{3}$ Yifei Jia $\left(D,{ }^{1}\right.$ and Chong Li $^{1}$ \\ ${ }^{1}$ School of Architecture and Civil Engineering, Xi'an University of Science and Technology, Xi'an 710061, China \\ ${ }^{2} X i$ 'an Key Laboratory of Geotechnical and Underground Engineering, Xi'an University of Science and Technology, \\ Xi'an 710061, China \\ ${ }^{3}$ School of Materials Science and Engineering, Chang'an University, Xi'an 710061, China \\ Correspondence should be addressed to Feng Liu; liufeng6621@qq.com
}

Received 30 January 2021; Revised 25 May 2021; Accepted 11 June 2021; Published 22 June 2021

Academic Editor: Marco Filippo Ferrotto

Copyright (c) 2021 Peili Su et al. This is an open access article distributed under the Creative Commons Attribution License, which permits unrestricted use, distribution, and reproduction in any medium, provided the original work is properly cited.

\begin{abstract}
For the cement-clay slurry commonly used in dynamic water grouting, consider adding coal ash to optimize the performance of cement-clay slag composite slurry and discuss the reaction mechanism of the slurry through microchemical element analysis; the orthogonal test was used to study the influence of various factors on material setting time, solidification ratio, water segregation rate, and the optimized ratio of the slurry that was obtained by integrating the unconfined compressive strength of grouting concretion body and slurry configuration cost. The results showed that the water-solid ratio had the greatest influence on the comprehensive performance, followed by the amount of coal ash admixture. The best performance of the composite slurry was obtained with a water-solid ratio of 0.8:1 and a cement:coal ash:clay:quicklime:sodium sulfate:water mass ratio of 1:0.45:0.20:0.05: $0.07: 1.32$. Finally, by comparing the mechanical properties of the optimized slurry and the grouting concretion body, it is proved that the optimized slurry has superior performance to meet the general grouting project requirement.
\end{abstract}

\section{Introduction}

With the implementation of China's western development strategy, underground projects such as tunnel construction and mine developments are gradually shifting to the central and westerly regions of the country. Meanwhile, the more complex geologic environment and frequent geological disasters come with it [1-3]. The information shows that water inrush is the most serious geological disaster that causes casualties and economic losses during tunnel construction. Among the causes of mine construction casualties, water penetration ranks second only to the gas explosion in all accidents [4]. Because of the strong applicability and significant effect of grouting technology in the prevention or control of water inrush and reinforcement of broken surrounding rocks, it is gradually applied in the construction fields such as mines, tunnels, and foundations [5-8].

Since the emergence of grouting technology, grouting materials have been constantly changing with their development. The properties of the grouting material directly affect the retention of the slurry in the water and the strength or stability of the grouting concretion body after hardening, which ultimately determines the quality of the grouting projects. For a successfully grouting process, it is necessary to consider the properties of the grouting material. At present, the slurry can be subdivided into organic grouting materials with urea-formaldehyde resin, acrylamide, lignin, and so on as the main raw materials and inorganic grouting materials based on cement according to its composition $[9,10]$. Due to the continuous progress of chemical technology, organic grouting materials have developed rapidly. Scholars have successfully developed chemical slurries such as the cement-water glass slurry $[11,12]$, coal ash-water glass two-component slurry [13], polymer slurry [14-16], and epoxy resin slurry [17-20] with different chemical reagents as the main materials and evaluated the basic properties or engineering applications of the slurries. However, the chemical slurry is expensive and 
generally toxic, which can easily lead to groundwater contamination; thus, its use is greatly restricted. Cement-based grout has become the preferred slurry for grouting projects due to the advantages of cheap raw materials, simple configuration, high strength after hardening, and less pollution [21]. Inorganic grouting materials can be divided into single cement slurry and cement-clay slurry. Single cement slurry is configured from construction raw material, cement, and its performance has been widely studied and mastered. Due to the disadvantages of pure cement slurry such as long hardening time and weak anti-washout property, related scholars have developed a new gangue grouting material for aquifer transformation [22], a new cement-based grouting material for water-rich fracture zone surrounding rock reinforcement [23], a new high-efficiency microfine cementbased grouting material [24], cement-based glass fiber grouting material [25], anti-swelling soft rock grouting material [26], and a series of cement-based composite slurries that improve the defects of single cement slurry.

In summary, many experts and scholars have conducted in-depth investigations on cement-clay slurry configuration or performance, and the research results have promoted the rapid development of the grouting discipline. By analyzing these studies, it can be noted that the existing researches are mostly focused on one type of clay addition, and the configuration was expensive, while the research on multiple clay slurry is few. Depending on this, this paper configures a lowcost clay slag composite slurry with ordinary Portland cement, coal ash, and clay as the main raw materials and quicklime and sodium sulfate as activators. The influence of slurry components on the properties of setting time, unconfined compressive strength, flexural strength, and the solidification ratio was studied through the orthogonal test. Moreover, the optimal design ratio of the composite slurry was finally obtained. The research conclusion has reference value for future compound slurry proportioning design and research.

\section{Reaction Mechanism}

According to the mechanism of cement hydration reaction, lime hydrolysis produces calcium hydroxide. $\mathrm{Ca}^{2+}$ and $\mathrm{OH}^{-}$ have a stimulating effect on coal ash. $\mathrm{H}^{+}$can destroy the $\mathrm{Si}-$ $\mathrm{O}$ and Al-O bonds of coal ash. Reactive silicon oxide, alumina, and calcium hydroxide react to produce an adsorption system of indeterminate components and then form hydrated calcium silicate and hydrated calcium aluminate. At the same time, calcium hydroxide and alumina react with sulfate in sodium sulfate to generate tricalcium aluminate hydrate and calcium sulfate, which forms calcium alumina in aqueous solution. $\mathrm{Ca}^{2+}$ in solution is combined with aluminate, sulfate, and silicate activated by coal ash in the excitation agent to generate hydrated calcium aluminate, and the result in $\mathrm{Ca}^{2+}$ is greatly reduced, which accelerates the hydration of cement clinker. The main chemical reaction formulae are as follows:

$$
\begin{aligned}
& \mathrm{SiO}_{2}+\mathrm{Ca}(\mathrm{OH})_{2}+n \mathrm{H}_{2} \mathrm{O} \longrightarrow \mathrm{CaO} \cdot \mathrm{SiO}_{2} \cdot(\mathrm{n}+1) \mathrm{H}_{2} \mathrm{O} \\
& \mathrm{Al}_{2} \mathrm{O}_{3}+\mathrm{Ca}(\mathrm{OH})_{2}+\mathrm{nH}_{2} \mathrm{O} \longrightarrow \mathrm{CaO} \cdot \mathrm{Al}_{2} \mathrm{O}_{3} \cdot(\mathrm{n}+1) \mathrm{H}_{2} \mathrm{O} \\
& \mathrm{Al}_{2} \mathrm{O}_{3} \cdot 2 \mathrm{SiO}_{2} \cdot 2 \mathrm{H}_{2} \mathrm{O}+\mathrm{Ca}(\mathrm{OH})_{2}+\mathrm{nH}_{2} \mathrm{O} \longrightarrow \mathrm{CaO} \cdot \mathrm{Al}_{2} \mathrm{O}_{3} \cdot 2 \mathrm{SiO}_{2} \cdot(\mathrm{n}+1) \mathrm{H}_{2} \mathrm{O} \\
& \mathrm{Fe}_{2} \mathrm{O}_{3}+\mathrm{Ca}(\mathrm{OH})_{2}+\mathrm{nH}_{2} \mathrm{O} \longrightarrow \mathrm{CaO}_{2} \cdot \mathrm{Fe}_{2} \mathrm{O}_{3} \cdot(\mathrm{n}+1) \mathrm{H}_{2} \mathrm{O}
\end{aligned}
$$

Under the action of the excitation agent, the hydrated calcium aluminate, hydrated calcium sulfate, and hydrated calcium silicate generated by the reaction in solution gradually become crystallized and accumulate. The crystalline mesh structure is formed between the crystals through strong chemical bonds, which makes the clay and hydration products interlinked and grow the strength and water stability of the crystalline body $[27,28]$.

\section{Experimental Materials and Design}

3.1. Orthogonal Test Materials. Qinling brand P.O. 32.5 ordinary Portland cement was used for the experiments; its chemical composition is shown in Table 1.

The coal ash is obtained from local commercial coal ash in Xi'an, and the main chemical components are shown in Table 2.

The clay is kaolin produced by Shanghai Fengcheng Reagent Factory, acquired by the laboratory, showing white color, and the technical conditions are shown in Table 3.
The quicklime used in the experiment was produced by Tianjin Kaitong Chemical Reagent Company, and its calcium oxide content was in accordance with the current standard JC/T479-1992 "Building Quicklime" of China's building materials industry, and the technical conditions are shown in Table 4 . The sodium sulfate used in the experiment is anhydrous sodium sulfate, and it was produced by Tianli Chemical Reagent Co., Ltd.

3.2. Experimental Content and Slurry Configuration. In the experiment, the effect of five experimental factors on the slurry performance was mainly considered: "A - watersolid ratio (the ratio of water to the total mass of cement, coal ash, and clay)," "B - mass percentage of coal ash to cement," " $\mathrm{C}$ - the mass percentage of clay to cement," "D - mass percentage of quicklime to cement," and "E - mass percentage of sodium sulfate to cement," and each factor had four levels, so orthogonal table L16 $\left(4^{5}\right)$ was used for the orthogonal test. The experimental scheme is shown in Tables 5 and 6. 
TABLE 1: Chemical composition of cement.

\begin{tabular}{lccccc}
\hline Composition & $\mathrm{SiO}_{2}(\%)$ & $\mathrm{CaO}(\%)$ & $\mathrm{Fe}_{2} \mathrm{O}_{3}(\%)$ & $\mathrm{Al}_{2} \mathrm{O}_{3}(\%)$ & $\mathrm{MgO}(\%)$ \\
\hline Content & 20.2 & 41.7 & 4.7 & 7.2 & 4.38 \\
\hline
\end{tabular}

TABLE 2: Chemical composition of coal ash.

\begin{tabular}{lccccccc}
\hline Composition & $\mathrm{SiO}_{2}(\%)$ & $\mathrm{Al}_{2} \mathrm{O}_{3}(\%)$ & $\mathrm{Fe}_{2} \mathrm{O}_{3}(\%)$ & $\mathrm{CaO}(\%)$ & $\mathrm{MgO}(\%)$ & $\mathrm{Na}_{2} \mathrm{O}(\%)$ & $\mathrm{K}_{2} \mathrm{O}(\%)$ \\
\hline Content & 50.6 & 27.1 & 7.1 & 2.8 & 1.2 & 0.5 & 1.3 \\
\hline
\end{tabular}

TABLE 3: Technical conditions of ceramic clay.

\begin{tabular}{lc}
\hline Ignition loss & $\leq 15 \%$ \\
Carbonate inspection & Eligible \\
Arsenic & $\leq 0.0002 \%$ \\
Heavy metal & $\leq 0.001 \%$ \\
Iron salt inspection & Eligibility \\
Chloride & $\leq 0.037 \%$ \\
Soluble matter in acid & $\leq 1 \%$ \\
Sand quality inspection & Eligible \\
\hline
\end{tabular}

TABLE 4: Technical conditions of quicklime.

Calcium oxide content

Acetic acid insoluble matter

Chloride $(\mathrm{Cl})$

Nitrate

Heavy metal

Ammonia precipitates

Clarity test

Loss on ignition

Sulfate $\left(\mathrm{SO}_{4}\right)$

Iron

Alkali metal and magnesium

TABle 5: Orthogonal factors and levels.

\begin{tabular}{lccccc}
\hline Factors and levels & A & B & C & D & E \\
\hline 1 & $0.5: 1$ & 15 & 10 & 2 & 1 \\
2 & $0.8: 1$ & 25 & 15 & 3 & 3 \\
3 & $1: 1$ & 35 & 20 & 5 & 5 \\
4 & $1.5: 1$ & 45 & 25 & 7 & 7 \\
\hline
\end{tabular}

When the slurry is configured, the content of each component in the slurry is first calculated through the orthogonal experiment table; then the cement, fly ash, lime, and water are stirred with a mixer for $5 \sim 10 \mathrm{~min}$, mixed with the preconfigured sodium sulfate solution later after thorough mixing, and stirred again for 5 10 min until the composite slurry is free from obvious segregation.

\section{Experiment Results and Analysis}

The water separation rate, setting time, and solidification rate are essential for the study of slurry performance. The water separation rate and setting time directly affect the spreading distance and hardening time of the slurry in the injected rock, while the solidification rate affects the volume and strength of the slurry after hardening. Therefore, the experiment focuses on the results of these three indicators to analyze the performance of each proportion of slurry. The water separation rate test is with reference to the "Technical Specification for Construction of Cement Grouting for Hydraulic Buildings" (SL62-2014) and the final setting time test is with reference to the "Test Method for Water Consumption, Setting Time, and Settlement of Cement Standard Consistency" (GBT1346-2011). The results of the experimental tests are shown in Table 7.

Table 7 shows that the slurry density, viscosity, and solidification rate decrease with the increase of the watersolid ratio, and the final setting time and water separation rate increase with the increase of the water-solid ratio. The viscosity of the slurry depends on the interior flocculation structure of the slurry, and the flocculation structure of the slurry with different water-solid ratios is shown in Figure 1. The water-solid ratio increases, and the internal water filling volume of the slurry increases; the slurry particles hydrate to form independent flocculation units, but it is difficult for the overall agglomeration to occur; the internal resistance decreases, and the viscosity decreases. On the contrary, the water-solid ratio decreases, and it is easier for the cement particles to agglomerate to form interlinked flocs; the internal pore space decreases after the slurry stable; the internal resistance of the slurry increases; and the slurry viscosity increases. Regarding the setting time, the water used for hydration of cement is only equivalent to $5 \% \sim 25 \%$ of the weight of cement. Therefore, the larger the water-solid ratio, the more the water is separated from the slurry and the longer the water separation time, resulting in the increase of the slurry solidification time.

Meanwhile, the data in Table 7 shows that the slurry water separation rate is less than $5 \%$ for water-solid ratios of $0.5: 1$ and $0.8: 1$, which is in accordance with the criterion of stable slurry [30]. As far as the solidification rate is concerned, the watersolid ratio of $0.5: 1$ and $0.8: 1$ is greater than $90 \%$, and the solidification rate is high. In terms of viscosity, the slurry with a water-solid ratio of 0.5:1 has a high viscosity and low fluidity, so it is unsuitable for general grouting works.

The data acquired were analyzed by the method of range analysis, and the primary and secondary relationships of the influence of each factor on slurry viscosity, water precipitation rate, initial setting times, and final setting times were obtained, as shown in Tables 8-11, respectively. 
TABLE 6: Orthogonal experimental design.

\begin{tabular}{|c|c|c|c|c|c|c|}
\hline Experiment number & Factor-level distribution & $\mathrm{A}$ & $\mathrm{B}$ & $\mathrm{C}$ & $\mathrm{D}$ & $\mathrm{E}$ \\
\hline 1 & A1B1C4D3E2 & $0.5: 1$ & 15 & 25 & 5 & 3 \\
\hline 2 & $\mathrm{~A} 1 \mathrm{~B} 2 \mathrm{C} 3 \mathrm{D} 2 \mathrm{E} 3$ & $0.5: 1$ & 25 & 20 & 3 & 5 \\
\hline 3 & $\mathrm{~A} 1 \mathrm{~B} 3 \mathrm{C} 1 \mathrm{D} 4 \mathrm{E} 4$ & $0.5: 1$ & 35 & 10 & 7 & 7 \\
\hline 4 & A1B4C2D1E1 & $0.5: 1$ & 45 & 15 & 2 & 1 \\
\hline 5 & A2B1C1D1E3 & $0.8: 1$ & 15 & 10 & 2 & 5 \\
\hline 6 & $\mathrm{~A} 2 \mathrm{~B} 2 \mathrm{C} 2 \mathrm{D} 4 \mathrm{E} 2$ & $0.8: 1$ & 25 & 15 & 7 & 3 \\
\hline 7 & $\mathrm{~A} 2 \mathrm{~B} 3 \mathrm{C} 4 \mathrm{D} 2 \mathrm{E} 1$ & $0.8: 1$ & 35 & 25 & 3 & 1 \\
\hline 8 & $\mathrm{~A} 2 \mathrm{~B} 4 \mathrm{C} 3 \mathrm{D} 3 \mathrm{E} 4$ & $0.8: 1$ & 45 & 20 & 5 & 7 \\
\hline 9 & $\mathrm{~A} 3 \mathrm{~B} 1 \mathrm{C} 3 \mathrm{D} 4 \mathrm{E} 1$ & $1: 1$ & 15 & 20 & 7 & 1 \\
\hline 10 & $\mathrm{~A} 3 \mathrm{~B} 2 \mathrm{C} 4 \mathrm{D} 1 \mathrm{E} 4$ & $1: 1$ & 25 & 25 & 2 & 7 \\
\hline 11 & A3B3C2D3E3 & $1: 1$ & 35 & 15 & 5 & 5 \\
\hline 12 & A3B4C1D2E2 & $1: 1$ & 45 & 10 & 3 & 3 \\
\hline 13 & $\mathrm{~A} 4 \mathrm{~B} 1 \mathrm{C} 2 \mathrm{D} 2 \mathrm{E} 4$ & $1.5: 1$ & 15 & 15 & 3 & 7 \\
\hline 14 & A4B2C1D3E1 & $1.5: 1$ & 25 & 10 & 5 & 1 \\
\hline 15 & A4B3C3D1E2 & $1.5: 1$ & 35 & 20 & 2 & 3 \\
\hline 16 & A4B4C4D4E3 & $1.5: 1$ & 45 & 25 & 7 & 5 \\
\hline
\end{tabular}

TABLE 7: Results of the orthogonal experiment.

\begin{tabular}{|c|c|c|c|c|c|c|}
\hline \multirow[t]{2}{*}{ Experiment number } & \multirow[t]{2}{*}{ Density } & \multirow[t]{2}{*}{ Viscosity } & \multicolumn{2}{|c|}{$\begin{array}{l}\text { Setting time } \\
(\min )\end{array}$} & \multirow[t]{2}{*}{ Water separation rate $(\%)$} & \multirow[t]{2}{*}{ Solidification rate (\%) } \\
\hline & & & Initial & Final & & \\
\hline 1 & 1.80 & - & 7.50 & 12.83 & 0.2 & 99.5 \\
\hline 2 & 1.80 & - & 6.58 & 12.42 & 0.5 & 99.3 \\
\hline 3 & 1.80 & - & 7.00 & 12.25 & 1.0 & 98.3 \\
\hline 4 & 1.79 & - & 7.58 & 13.17 & 1.0 & 98.8 \\
\hline 5 & 1.58 & 32 & 11. 75 & 20.92 & 4.2 & 95.0 \\
\hline 6 & 1.56 & 33 & 12.08 & 21.25 & 2.5 & 93.3 \\
\hline 7 & 1.50 & 29 & 12.50 & 21.75 & 3.1 & 93.3 \\
\hline 8 & 1.53 & 31 & 13.25 & 23.08 & 4.2 & 93.3 \\
\hline 9 & 1.44 & 25 & 19.58 & 30.08 & 7.0 & 86.3 \\
\hline 10 & 1.43 & 24 & 20.25 & 31.08 & 5.1 & 91.3 \\
\hline 11 & 1.45 & 23 & 19.08 & 29.25 & 15.1 & 88.3 \\
\hline 12 & 1.43 & 22 & 20.75 & 31.25 & 13.0 & 87.5 \\
\hline 13 & 1.32 & 20 & 30.75 & 47.92 & 37.4 & 68.8 \\
\hline 14 & 1.32 & 20 & 31.25 & 48.58 & 30.5 & 71.8 \\
\hline 15 & 1.32 & 18 & 31.08 & 48.17 & 43.6 & 66.3 \\
\hline 16 & 1.34 & 18 & 31.58 & 49.17 & 30.5 & 72.0 \\
\hline
\end{tabular}

Note. "-" means that the viscosity is very high and almost does not flow.

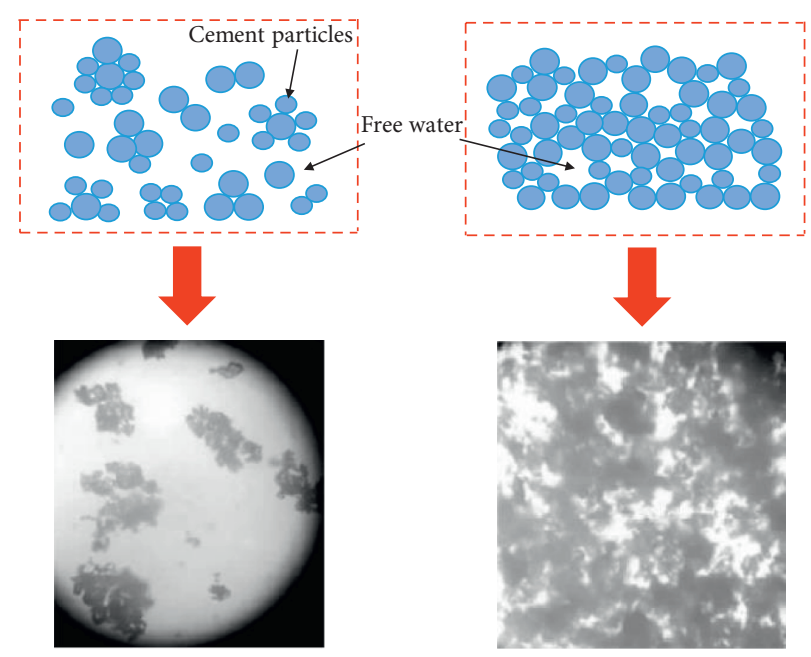

(a)

(b)

FIGURE 1: Flocculation structure diagram of cement slurries with different water-solid ratios [29]: (a) high water-solid ratio slurry and (b) low water-solid ratio slurry. 
TABLE 8: Range analysis of slurry viscosity.

\begin{tabular}{lccccc}
\hline \multirow{2}{*}{ Analysis index } & \multicolumn{5}{c}{ Factors } \\
& $\mathrm{A}$ & $\mathrm{B}$ & $\mathrm{C}$ & $\mathrm{D}$ & $\mathrm{E}$ \\
\hline$K_{1}$ & $+\infty$ & 25.71 & 24.43 & 24.83 & 24.71 \\
$K_{2}$ & 31.37 & 25.74 & 25.64 & 23.88 & 24.38 \\
$K_{3}$ & 23.66 & 23.40 & 24.67 & 24.64 & 24.37 \\
$K_{4}$ & 18.95 & 23.80 & 23.91 & 25.63 & 25.19 \\
Range & $+\infty$ & 2.34 & 1.73 & 1.75 & 0.82 \\
Primary and secondary factors & \multicolumn{5}{c}{$\mathrm{A}>\mathrm{B}>\mathrm{D}>\mathrm{C}>\mathrm{E}$} \\
\hline
\end{tabular}

Note. $K_{1}, K_{2}, K_{3}$, and $K_{4}$ are the average values of test results corresponding to levels $1,2,3$, and 4 , respectively.

TABle 9: Range analysis of slurry water separation rate.

\begin{tabular}{lccccc}
\hline \multirow{2}{*}{ Analysis index } & \multicolumn{5}{c}{ Factors } \\
& $\mathrm{A}$ & $\mathrm{B}$ & $\mathrm{C}$ & $\mathrm{D}$ & $\mathrm{E}$ \\
\hline$K_{1}$ & 0.68 & 12.20 & 12.18 & 13.48 & 10.40 \\
$K_{2}$ & 3.50 & 9.65 & 14.00 & 13.50 & 14.82 \\
$K_{3}$ & 10.05 & 15.70 & 13.82 & 12.50 & 12.58 \\
$K_{4}$ & 35.50 & 12.28 & 9.72 & 10.25 & 11.92 \\
Range & 34.82 & 6.05 & 4.28 & 3.25 & 4.42 \\
Primary and secondary factors & \multicolumn{5}{c}{$\mathrm{A}>\mathrm{B}>\mathrm{E}>\mathrm{C}>\mathrm{D}$} \\
\hline
\end{tabular}

TABLE 10: Range analysis of the initial setting time of slurry.

\begin{tabular}{lccccc}
\hline \multirow{2}{*}{ Analysis index } & \multicolumn{5}{c}{ Factors } \\
& $\mathrm{A}$ & $\mathrm{B}$ & $\mathrm{C}$ & $\mathrm{D}$ & $\mathrm{E}$ \\
\hline$K_{1}$ & 7.17 & 17.40 & 17.69 & 17.67 & 17.73 \\
$K_{2}$ & 12.40 & 17.54 & 17.50 & 17.65 & 17.85 \\
$K_{3}$ & 19.92 & 17.42 & 17.62 & 17.77 & 17.21 \\
$K_{4}$ & 31.17 & 18.25 & 17.92 & 17.52 & 17.81 \\
Range & 24 & 0.85 & 0.42 & 0.25 & 0.64 \\
Primary and secondary factors & \multicolumn{5}{c}{$\mathrm{A}>\mathrm{B}>\mathrm{E}>\mathrm{C}>\mathrm{D}$} \\
\hline
\end{tabular}

TABLE 11: Range analysis of the final setting time of slurry.

\begin{tabular}{lccccc}
\hline \multirow{2}{*}{ Analysis index } & \multicolumn{5}{c}{ Factors } \\
& $\mathrm{A}$ & $\mathrm{B}$ & $\mathrm{C}$ & $\mathrm{D}$ & $\mathrm{E}$ \\
\hline$K_{1}$ & 12.67 & 27.94 & 28.25 & 28.34 & 28.40 \\
$K_{2}$ & 21.75 & 28.33 & 28.06 & 28.34 & 28.38 \\
$K_{3}$ & 30.42 & 27.86 & 28.44 & 28.44 & 27.94 \\
$K_{4}$ & 48.46 & 29.17 & 28.71 & 28.19 & 28.58 \\
Range & 35.79 & 1.31 & 0.65 & 0.25 & 0.64 \\
Primary and secondary factor & \multicolumn{5}{c}{$\mathrm{A}>\mathrm{B}>\mathrm{C}>\mathrm{E}>\mathrm{D}$} \\
\hline
\end{tabular}

It can be concluded from Tables 8-11 that the water-solid ratio is the primary factor affecting the physical properties of the slurry, followed by the mass percentage of coal ash to cement. Therefore, when selecting the optimal composite slurry ratio, the influence of the water-solid ratio should be considered first, followed by the proportion of coal ash content admixture.

In summary, the slurry with a water-solid ratio of 0.8:1 was initially selected as the best mix ratio. Moreover, a water-solid ratio of 0.8:1 was selected for the next mechanical test as shown in Table 6 (groups 5, 6, 7, and 8).

4.1. Mechanical Properties Test of Serous Calculus. Strength is the most important mechanical property of the grouting concretion body. Mechanical tests of the grouting

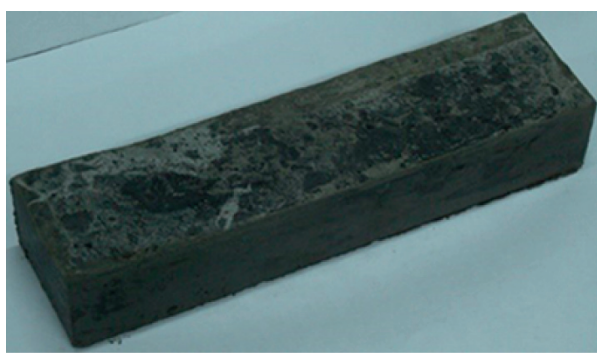

FIgURE 2: Molding sample.

concretion body in this section include unconfined compressive and flexural strengths. According to the orthogonal test design table, a composite slurry with different material ratios and a water-solid ratio of 0.8:1 is configured. After the slurry is fully mixed, it is immediately poured into a triple cement test mold with the size of $40 \mathrm{~mm} \times 40 \mathrm{~mm} \times 160 \mathrm{~mm}$, and the mold is released after the slurry has gelled. Finally, the test blocks are placed in the water with a curing temperature of $20 \pm 5^{\circ} \mathrm{C}$ for curing, and the strength of the blocks is tested for curing cycles of $3 \mathrm{~d}, 7 \mathrm{~d}, 14 \mathrm{~d}$, and $28 \mathrm{~d}$. The molded sample is shown in Figure 2.

The flexural and compressive strengths of the grouting concretion body were measured by DKZ-5000 electric flexural testing machine (Figure 3(a)) and NYL-300C pressure testing machine (Figure 3(b)). During the test, the arithmetic average value of three specimens is used as the flexural (compressive) strength value of the group of specimens. If the maximum or minimum of the three values exceeds $15 \%$ of the median value, the maximum and minimum values are discarded together, and the middle value is selected as the flexural (compressive) strength of the group of specimens. If the difference between the two measured values and the middle exceeds $15 \%$ of the middle value, the result of this group of specimens is invalid.

The mechanical test results of grouting concretion bodies at different curing ages are drawn on a graph, and the final result is shown in Figure 4.

It can be observed from Figure 4 that the unconfined compressive and flexural strengths of the slurry cement on each ratio increase with time when the water-solid ratio is the same. The overall trend of the curve in the graph shows that: (1) the mechanical properties of the No. 6 grouting concretion body is the best at different curing times, and the No. 7 has the worst mechanical properties. When the maintenance interval is $3 \mathrm{~d}$, the compressive and flexural strengths of No. 6 are $4.28 \mathrm{MPa}$ and $0.965 \mathrm{MPa}$, respectively, and of No. 7 are $1.114 \mathrm{MPa}$ and $0.308 \mathrm{MPa}$, respectively. The differences in compressive and flexural strengths between No. 6 and 7 are $3.17 \mathrm{MPa}$ and $0.66 \mathrm{MPa}$, respectively, and reach $4.99 \mathrm{MPa}$ and $1.16 \mathrm{MPa}$, respectively, at $28 \mathrm{~d}$. (2) The mechanical properties of grouting concretion bodies between Nos. 6 and 8 are not much different. When the maintenance interval is $3 \mathrm{~d}$, the compressive and flexural strengths of No. 8 are $3.821 \mathrm{MPa}$ and $0.935 \mathrm{MPa}$, respectively, which decrease $0.03 \mathrm{MPa}$ and $0.46 \mathrm{MPa}$, respectively, compared with No. 6; when the curing cycle reaches $28 \mathrm{~d}$, the compressive and flexural strengths of No. 8 are reduced by $0.06 \mathrm{MPa}$ and $0.33 \mathrm{MPa}$, respectively, compared with No. 6 . 


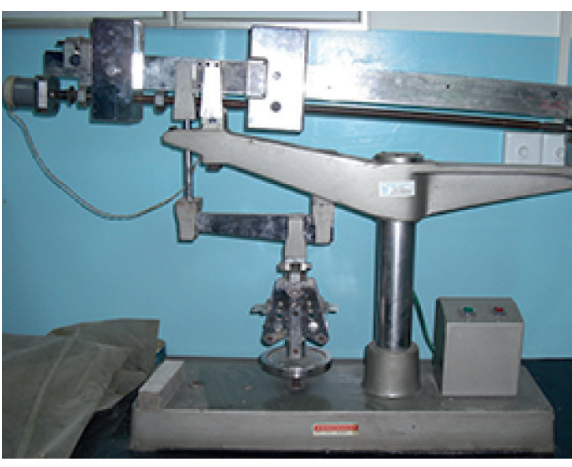

(a)

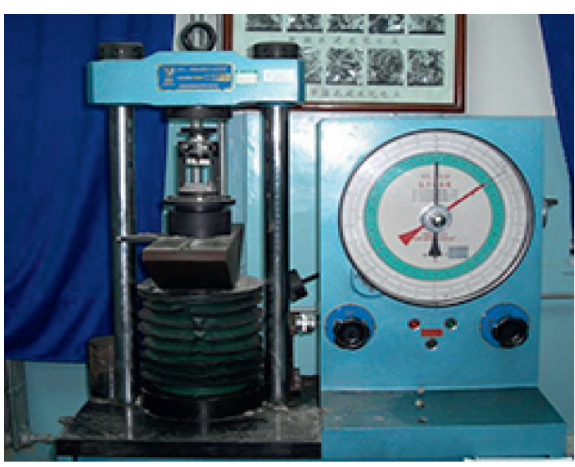

(b)

FIGURE 3: Strength test equipment: (a) DKZ-5000 electric flexural testing machine and (b) NYL-300C pressure testing machine.

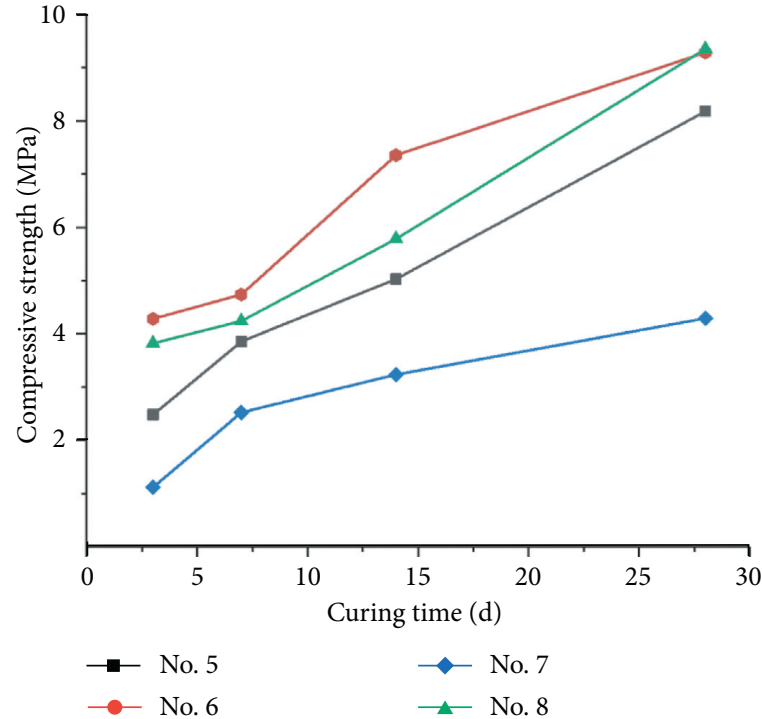

(a)

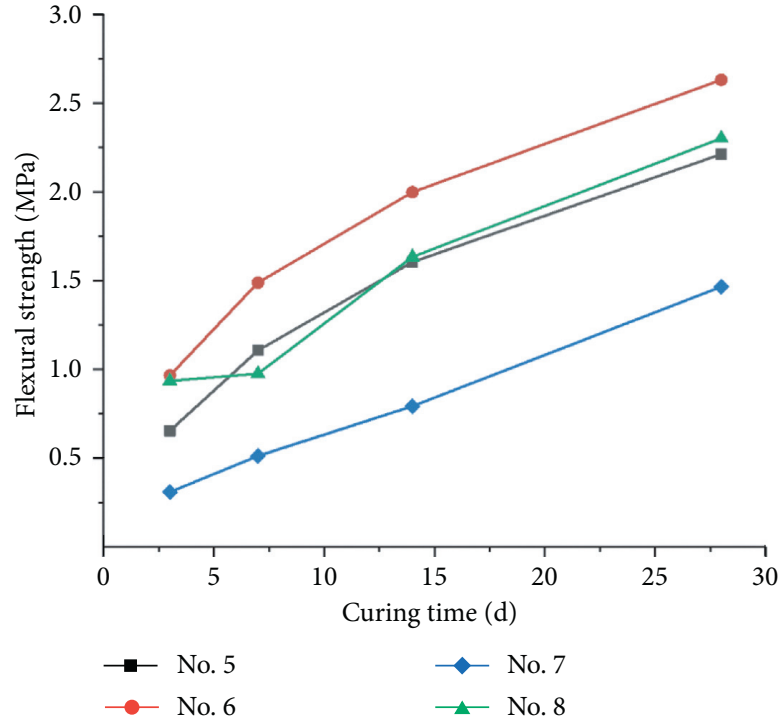

(b)

FiguRE 4: Mechanical properties of slurry with a water-solid ratio of 0.8:1 at different curing ages: (a) curve of unconfined compressive strength with time and (b) curve of flexural strength with time.

The above analysis results are synthesized, while taking into account the economic benefits brought by different coal ash content; No. 8 (the mass ratio of cement:coal ash:clay: quicklime:sodium sulfate:water is 1:0.45:0.20:0.05:0.07:1.32) was finally selected as the best ratio for the composite slurry. In the optimized composite slurry (No. 8), a certain amount of water glass was added (the Baume degree of water glass was $35^{\circ} \mathrm{B}$, and the volume ratio of water glass to cement composite slurry was $0.6: 1$ ), and the initial setting time of the slurry was measured to be about $10 \mathrm{~s}$, indicating that the addition of water glass solution can effectively regulate the setting time of the composite slurry. By analyzing the reasons, the existence of water glass solution accelerates the consumption of cement hydrate calcium hydroxide to generate hydrated calcium silicate $\left(\mathrm{CaO} \cdot \mathrm{nSiO}_{2} \cdot \mathrm{mH}_{2} \mathrm{O}\right)$. The specific reaction equations are as follows [31]:

$$
\mathrm{Ca}(\mathrm{OH})_{2}+\mathrm{Na}_{2} \mathrm{O} \cdot \mathrm{nSiO}_{2}+\mathrm{mH}_{2} \mathrm{O} \longrightarrow \mathrm{CaO} \cdot \mathrm{nSiO}_{2} \cdot \mathrm{mH}_{2} \mathrm{O}+2 \mathrm{NaOH}
$$

Due to the rapid reaction of the water glass solution with calcium hydroxide, the gelation time of the cement-water glass slurry will be reduced substantially. Therefore, the amount of water glass added can be determined according to the geological conditions to control the gelling time of the slurry, so that the grouting can be controlled. 


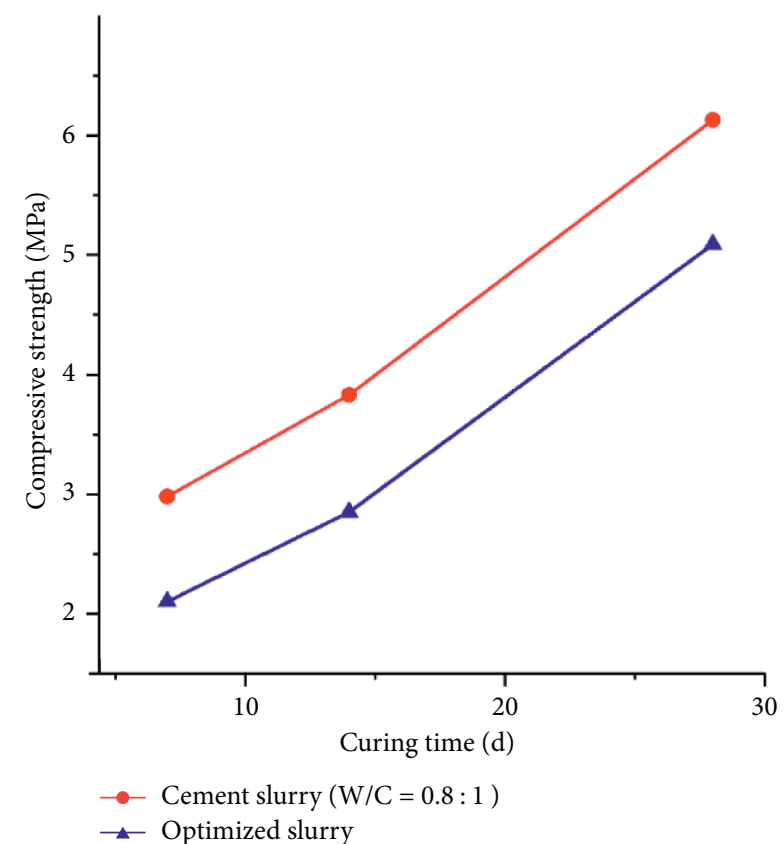

Figure 5: Comparison of strength between pure cement slurry and optimized slurry in different ages.

\section{Optimization of Slurry Performance Testing}

To further evaluate the engineering practicality of the optimized slurry, it is necessary to conduct a comparison test of the mechanical properties between the optimized slurry and ordinary cement slurry. The specific test methods are as follows: two types of slurry were prepared before the experiment; one group of slurry is mixed with the best ratio obtained above (No. 8), and the other group is mixed with a pure cement slurry with a water-cement ratio of $0.8: 1$. After mixing evenly, the two slurries are poured into two identical standard molds $(100 \mathrm{~mm} \times 100 \mathrm{~mm} \times 100 \mathrm{~mm})$ and then we vibrate and compact the slurries to make them dense. The specimens were left to solidify for $24 \mathrm{~h}$ before release from the mold and then placed in a curing box under standard conditions for curing. Specimens were taken out with curing ages of $7 \mathrm{~d}, 14 \mathrm{~d}$, and $28 \mathrm{~d}$ for the compressive strength test. Finally, the results of the compressive strength tests of the specimens at different curing ages are plotted in a graph, as shown in Figure 5.

It can be observed from Figure 5 that the optimized slurry grouting concretion body compressive strength at different curing ages is lower than that of the cement slurry, but the strength increase trend is the same as that of cement slurry. The general trend of the curves in the graph shows that the global difference in compressive strength between two slurry concretions is moderate. The difference in compressive strength between the optimized slurry and the cement slurry is $0.9 \mathrm{kPa}$ at $7 \mathrm{~d}, 1 \mathrm{kPa}$ at $14 \mathrm{~d}$, and $1.1 \mathrm{kPa}$ at $28 \mathrm{~d}$. However, because the mass percentage of coal ash and cement in the optimized slurry is up to $45 \%$, the mixing of coal ash reduces the cost of slurry configuration. Therefore, for general grouting reinforcement works, priority can be given to grouting with optimized proportioned slurry.

\section{Conclusions}

(1) The performance of the cement-clay-slag composite slurry was investigated by orthogonal tests. The results show that the comprehensive performance of slurry is the best when the water-solid ratio is $0.8: 1$. Combining the cost of slurry configuration and mechanical properties of the grouting concretion body, group 8 slurry (the mass ratio of cement:coal ash:clay:quicklime:sodium sulfate:water is $1: 0.45$ : $0.20: 0.05: 0.07: 1.32$ ) was selected as the optimized composite slurry.

(2) The range analysis of orthogonal test results shows that the water-solid ratio is the primary factor affecting the performance of composite slurry, and the coal ash is the second. In the process of slurry configuration, the influence of water-solid ratio and coal ash content on the comprehensive performance of slurry should be considered first.

(3) The experiment shows that water glass can effectively adjust the setting time of composite slurry. Therefore, when designing the slurry ratio in the early stage of a project, a certain amount of water glass can be considered to be added to control the hardening time so that the grouting work can be controlled.

(4) By comparing the physical strength of the grouting concretion body at different curing ages of optimized slurry and cement slurry with a water-cement ratio of 0.8 , the results show that the strength of optimized slurry is lower than that of pure cement slurry, but the difference in strength is small. Moreover, the strength growth trend of composite slurry during hardening is as stable as that of pure cement slurry, indicating that composite slurry has good performance.

\section{Data Availability}

The data supporting this research article are available from the corresponding author upon request.

\section{Conflicts of Interest}

The authors declare that they have no conflicts of interest.

\section{Acknowledgments}

The authors gratefully acknowledge the financial support of the 2020 Open Fund of Xi'an Key Laboratory of Geotechnical and Underground Engineering (no. XKLGUEKF2003) and the Shaanxi Natural Science Basic Research Program (no. 2018JM5126). 


\section{References}

[1] Q. H. Qian, "Challenges faced by underground projects construction safety and countermeasures," Chinese Journal of Rock Mechanics and Engineering, vol. 31, no. 10, pp. 19451956, 2012.

[2] K. R. Hong, "Development and thinking of tunnels and underground engineering in China in recent 2 years (From 2017 to 2018)," Tunnel Construction, vol. 39, no. 5, pp. 710$723,2019$.

[3] L. P. Li, S. Cheng, Y. H. Zhang et al., "Opportunities and challenges of construction safety in underground engineering projects," Journal of Shandong University of Science and Technology, vol. 39, no. 4, pp. 1-13, 2020.

[4] X. Zhang, "Study on mechanism of slurry diffusion and sealing at the process of underground engineering moving water grouting and its application," Ph. D thesis, Shandong University, Jinan, China, 2011.

[5] K. Kikuchi, T. Igari, Y. Mito, and S. Utsuki, "In situ experimental studies on improvement of rock masses by grouting treatment," International Journal of Rock Mechanics and Mining Sciences, vol. 34, pp. 3-4, 1997.

[6] M. J. Yang, M. X. Chen, and Y. N. He, "Current research state of grouting technology and its development direction in future," Chinese Journal of Rock Mechanics and Engineering, vol. 20 , no. 6, pp. 839-841, 2001.

[7] D. Gouvenot, "State of the art in European grouting," Proceedings of the ICE-Ground Improvement, vol. 2, no. 2, pp. 51-67, 2010.

[8] A. Draganović and H. Stille, "Filtration and penetrability of cement-based grout: study performed with a short slot," Tunnelling and Underground Space Technology incorporating Trenchless Technology Research, vol. 26, no. 4, pp. 548-559, 2011.

[9] X. L. Wang, Q. R. Qin, P. D. Su et al., "Research status and development tendency of fractured surrounding rock grunting reinforcement technology," Science Technology and Engineering, vol. 17, no. 23, pp. 122-131, 2017.

[10] H. P. Kang and Z. Q. Feng, "Status and development tendency of roadway grouting reinforcement technology in coal mine," Coal Mining Technology, vol. 18, no. 3, pp. 1-7, 2013.

[11] Q. S. Zhang, L. Z. Zhang, R. T. Liu et al., "Laboratory experimental study of cement-silicate slurry diffusion law of crack grouting with dynamic water," Rock and Soil Mechanics, vol. 36, no. 8, pp. 2159-2168, 2015.

[12] Z. F. Li, Y. F. Gao, J. Zhang et al., "Experimental study of water-soluble vegetable gum-modified cement-sodium silicate plugging materials," Chinese Journal of Rock Mechanics and Engineering, vol. 42, no. 7, pp. 1312-1321, 2020.

[13] H. B. Wang, Q. S. Zhang, R. T. Liu et al., "Test and process research of poor geological dynamic water plugging reinforcement material," Chinese Journal of Rock Mechanics and Engineering, vol. 36, no. S2, pp. 3984-3991, 2017.

[14] C. A. Anagnostopous, "Laboratory study of an injected granular soil with polymer grouts," Tunnelling and Underground Space Technology, vol. 20, no. 06, pp. 525-533, 2005.

[15] C. Zhang, J. S. Yang, J. Y. Fu et al., "Optimal formulation design of polymer-modified cement based grouting material for loose deposits," Construction and Building Materials, vol. 261, Article ID 120513, 2020.

[16] W. Z. Wang, W. Q. Zhao, J. J. Zhang, and J. H. Zhou, "Epoxybased grouting materials with super-low viscosities and improved toughness," Construction and Building Materials, vol. 267, no. 1, Article ID 121104, 2020.

[17] X. C. Gao, Y. P. Wu, and X. D. Liu, "Preparation and application of new vinyl epoxy resin grouting material for sand consolidation," Safety In Coal Mines, vol. 47, no. 5, pp. 151153, 2016

[18] H. W. Zhu, C. W. Liu, X. Q. Chen, and C. Zhao, "Experimental study on mortar materials with fissures filled with high permeability modified epoxy resin," Bulletin of the Chinese Ceramic Society, vol. 40, no. 1, pp. 77-82, 2021.

[19] C. H. Wang, Z. T. Fan, C. H. Li, H. J. Zhang, and X. D. Xiao, "Preparation and engineering properties of low-viscosity epoxy grouting materials modified with silicone for microcrack repair," Construction and Building Materials, vol. 290, Article ID 123270, 2021.

[20] G. C. Yan, L. J. Bai, Z. Q. Zhang et al., "Experimental and applied study on pu modified sulphoaluminate cement grouting material," Journal of China Coal Society, vol. 1-7, 2021.

[21] Y. Jiang, F. Guo, H. Kong et al., "Current situation and development strategies of grouting materials," New Chemical Materials, vol. 1-13, 2021.

[22] H. T. Wang, X. C. Wang, M. H. Zhai et al., "Experiment and application of new materials for grouting of gangue-based aquifer," Journal of China Coal Society, vol. 42, no. 11, pp. 2981-2988, 2017.

[23] S. S. Li, "Property optimization test of new cement-based grouting material," Coal Technology, vol. 36, no. 8, pp. 169-170, 2017.

[24] F. Sha, S. C. Li, R. T. Liu et al., "Performance and engineering application of effective microfine cement-based grout (EMCG) for water-rich sand strata," Chinese Journal of Rock Mechanics and Engineering, vol. 38, no. 7, pp. 1420-1433, 2019.

[25] Q. K. Zhu, “Application of cement-based fiber glass slurry in tunnel grouting and water plugging," Journal of Yangtze River Scientific Research Institute, vol. 36, no. 6, pp. 133-138, 2019.

[26] X. M. Sun, F. Chen, G. F. Liang et al., "Experimental and application research on grouting material for preventing swelling of soft rock," Chinese Journal of Rock Mechanics and Engineering, vol. 36, no. 2, pp. 457-465, 2017.

[27] L. Z. Zhang, W. Chen, X. L. Zhou et al., "The engineering performance of cement-fly ash-clay grout," Journal of Hunan Institute of Engineering, vol. 24, no. 4, pp. 76-79, 2014.

[28] P. F. Gou and Y. S. Zhang, "Performance experiment on solidifying slurry of cement-clay-fly ash-quicklime," Journal of China Coal Society, vol. 27, no. 2, pp. 148-151, 2002.

[29] L. J. Wang, X. Q. Tan, and M. L. Cao, "Study of cement flocculation," Concrete, vol. 01, pp. 29-31, 2007.

[30] X. L. Rao, "The study and application of the steady cement paste," M.S. thesis, Central South University, Changsha, China, 2009.

[31] Z. Q. Zhen, "Study on grouting performance and engineering application of water glass material," M.S. thesis, Taiyuan University of Technology, Taiyuan, China, 2019. 